\title{
Das Bessere ist der Feind des Guten!
}

\section{Urs Stoffel}

Dr. med., Mitglied des Zentralvorstandes, Departementsverantwortlicher Ambulante Versorgung und Tarife

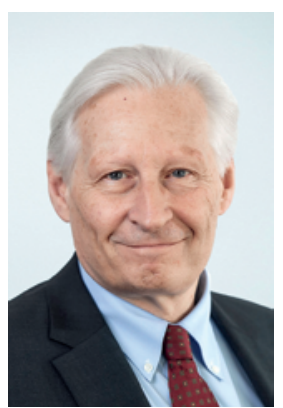

«Das Bessere ist der Feind des Guten» - dieser Aphorismus, der dem grossen französischen Philosophen und Schriftsteller Voltaire zugeschrieben wird, umschreibt treffend die Situation, in der wir uns mit dem Projekt «Gesamtrevision TARMED» zurzeit befinden. Unter Hochdruck laufen im Moment die Verhandlungen mit den Tarifpartnern für einen gemeinsamen Tarif. Die Leistungsstruktur des FMH-internen Projekts TARCO war im Mai 2018 von der Ärztekammer einstimmig verabschiedet worden.

Die Ärzteschaft hat also seit Mai 2018 wieder einen Vorschlag für eine ausgewogene Leistungsstruktur (Nomenklatur) zur Abgeltung der ärztlichen Leistungen.

\section{Eine gemeinsam eingereichte Tarifstruktur} erlangen wir nur, wenn Leistungserbringer und Kostenträger Kompromissbereitschaft zeigen.

Damit hat sie eindrücklich ihre innere Konsensfähigkeit bewiesen. Diese Leistungsstruktur reflektiert die ärztliche Sicht der aktuellen medizinischen Leistungen im ambulanten Bereich.

Nun gilt es, die Leistungsstruktur zusammen mit den Tarifpartnern in einen gemeinsamen Vorschlag für eine Tarifstruktur zu integrieren. Zurzeit laufen diese Verhandlungen mit den Tarifpartnern, denn der Vorschlag soll Ende Jahr gemeinsam dem Bundesrat zur Genehmigung eingereicht werden. Noch ist sehr viel zu tun, bis die Verhandlungen im September abgeschlossen werden sollen! Nach Abschluss muss das Verhandlungsresultat noch in den jeweiligen zuständigen Gremien der Tarifpartner genehmigt werden. Innerhalb der FMH werden dies das Cockpit TARCO, die Delegiertenversammlung und die Ärztekammer sein.

Eines ist sicher - das Ziel eines gemeinsamen Einreichens der Tarifstruktur können wir nur erreichen, wenn sowohl auf Seiten der Leistungserbringer wie auch auf Seiten der Kostenträger ein gemeinsamer und ehrlicher Wille besteht, endlich das Handlungsprimat im Tarifbereich wieder zu den Tarifpartnern zurückzuholen! Das Know-how für eine ausgewogene, sachgerechte und betriebswirtschaftlich bemessene Tarifstruktur liegt ganz klar bei den Tarifpartnern. Dafür braucht es aber von beiden Seiten eine Konsensfähigkeit und eine Kompromissbereitschaft, um diese Tarifstruktur gemeinsam zu erarbeiten und auch weiter zu entwickeln.

Denn eines steht jetzt schon fest: Wir werden keine rundum perfekte und definitiv abgeschlossene Tarifstruktur einreichen können, bei der sowohl Leistungserbringer als auch Kostenträger in Jubelgeschrei ausbrechen. Das Ziel ist es, eine gute und pragmatische Tarifstruktur einzureichen. Entscheidend wird sein, sich zu einigen, wie wir mit den zweifellos noch bestehenden Dissensen bei der Einführung der Tarifstruktur umgehen. Sie ist ein work in progress und braucht eine kontinuierliche und gemeinsame Pflege und Weiterentwicklung durch die Tarifpartner - mit klaren Prozessen und Zuständigkeiten.

Eine laufende Pflege und Weiterentwicklung der Tarifstruktur ist das A und O. Ansonsten wird sie nach kurzer Zeit die Vorgaben der Sachgerechtigkeit und der betriebswirtschaftlichen Bemessung nicht mehr erfüllen können. Das mussten wir seit der Einführung des TARMED 2004 durch die permanente Blockade eines Tarifpartners, der sich auch jetzt wieder verweigert,

\section{Die Frage lautet: Können wir mit der} verhandelten Tarifstruktur in eine gemeinsame tarifpartnerschaftliche Zukunft starten ?

nur allzu schmerzlich erfahren. Die fehlende Pflege und Weiterentwicklung ist für den grössten Teil unserer heutigen Probleme verantwortlich.

Die Frage muss also nicht lauten, ob wir eine rundum perfekte Tarifstruktur geschaffen haben, andernfalls ist sie abzulehnen, sondern vielmehr: Können wir mit dieser verhandelten Tarifstruktur in eine gemeinsame, tarifpartnerschaftliche Zukunft starten? Wie gehen wir mit den bestehenden Differenzen und Unwuchten um und wie pflegen und entwickeln wir diese Tarifstruktur gemeinsam weiter? 